2003

\title{
Does Opening A Stock Exchange Increase Economic Growth?
}

Scott L. Baier

Clemson University

Gerald P. Dwyer, Jr.

Federal Reserve Bank of Atlanta, gdwyer@dwyerecon.com

Robert Tamura

Clemson University

Follow this and additional works at: https://fordham.bepress.com/crif_seminar_series

Part of the Finance and Financial Management Commons

\section{Recommended Citation}

Baier, Scott L.; Dwyer, Jr., Gerald P.; and Tamura, Robert, "Does Opening A Stock Exchange Increase Economic Growth?" (2003). CRIF Seminar series. 28.

https://fordham.bepress.com/crif_seminar_series/28 
Does Opening A Stock Exchange Increase Economic Growth?

\author{
Scott L. Baier \\ Clemson University \\ 222 Sirrine Hall \\ Clemson, SC 29634-1309 \\ Gerald P. Dwyer, Jr.* \\ Federal Reserve Bank of Atlanta \\ 1000 Peachtree Street, N.E. \\ Atlanta, GA 30309 \\ Robert Tamura \\ Clemson University \\ 222 Sirrine Hall \\ Clemson, SC 29634-1309
}

\begin{abstract}
We examine the connection between the creation of stock exchanges and economic growth with a new set of data on economic growth that spans a longer time period than generally available. We find that economic growth increases relative to the rest of the world after a stock exchange opens. Our evidence indicates that increased growth of productivity is the primary way that a stock exchange increases the growth rate of output, rather than an increase in the growth rate of physical capital. We also find that financial deepening is rapid before the creation of a stock exchange and slower subsequently.
\end{abstract}

JEL: G15, G10, G15, D90, O16.

Keywords: economic growth, stock exchange, efficiency, productivity, financial deepening.

*Corresponding author: Gerald P. Dwyer, Jr., Research Department, Federal Reserve Bank of Atlanta, 1000 Peachtree St. N.E., Atlanta GA 30309, e-mail gdwyer@ dwyerecon.com, phone 404498-7095, fax 404-498-8810. 


\section{INTRODUCTION}

Over the last decade there has been a growing body of literature examining the connection between economic growth and financial markets and intermediation. These studies indicate that "financial deepening" - generally measured by growth of a broad monetary aggregate relative to income - is positively correlated with economic growth, and several suggest that financial deepening is causal in the sense that financial deepening precedes higher economic growth (Levine 2002). There is at least one recently expressed reservation about the strength of the inference that can be drawn (Wachtel 2002).

Overall, this literature on financial development and economic growth suggests that financial development has a substantial effect on economic growth. As Atje and Jovanovic (1993) put it, "If it is true, then it is ... surprising that more countries are not developing their stock market as a means of speeding up their economic development." Despite attempts to draw this inference that planned financial development would spur growth, there have been few studies that investigate directly how the introduction of financial institutions affects economic growth. Perhaps the closest is the research by Bekaert, Harvey, and Lundblad (2003), who focus on liberalization of governments' restrictions on financial affairs in developing countries and find substantial effects. While informative, the estimated effects may be overstated because liberalizing equity markets generally is not the only reform in progress.

The purpose of this paper is to examine the connection between economic growth and the development of institutions that support the financial sector of economies. We focus on the creation of stock exchanges. While it would be interesting to examine the effect of the introduction of 
banking on economic growth, the dataset would have to extend well before the nineteenth century to make such an analysis possible. ${ }^{1}$ Stock exchanges can have profound effects on a country's financial system, and indeed, Rousseau and Sylla (2001) suggest that well functioning securities markets are one of five important components of a good financial system that supports economic growth.

Well functioning capital markets can increase economic efficiency, investment and growth. A new stock exchange can increase economic growth by aggregating information about firms' prospects, thereby directing capital to investment with returns (Greenwood and Jovanovic 1990; King and Levine 1993). These effects of a stock market opening result in a measured increase in productivity. Stock exchanges exist for the purpose of trading ownership rights in firms, and a new stock exchange may increase productivity growth for this reason as well. The creation of a stock exchange can increase economic growth by lowering the costs of exchanging ownership rights in firms, an important part of some institutional stories of economic growth (North 1991). A new stock market also can increase economic growth by reducing holdings of liquid assets and increasing the growth rate of physical capital (Bencivenga and Smith 1991), at least in the long run. In the shortrun, however, the equilibrium response of the capital stock to a new stock exchange can be negative because the opening of an exchange can increase households' wealth and raise their contemporaneous consumption enough to temporarily lower the growth rate of capital.

Most existing studies of financial development and growth focus on financial development from 1950 to 2000 because of a lack of data for many countries before World War II. As a result,

\footnotetext{
${ }^{1}$ Using techniques similar to those in this paper, we examined the effect of creating a domestic central bank operating as a lender of last resort and found little evidence of any connection with economic growth.
} 
any estimated effect of growth is specific to this fifty years, which may or may not be indicative of the typical or future effects. Moreover, most of the developments are after 1960 and most of the effects of developments in the 1990s will not be seen until after 2000. Finally, the common time frame means that common confounding events may have important effects on the results, and it is harder to put such concerns to rest than with a longer time period.

Fortunately, we are able to use a new dataset that extends over 100 years for many countries and includes information on the growth of physical capital, human capital and total factor productivity (TFP) in addition to real income growth (Baier, Dwyer and Tamura 2002). These data allow us to examine creation of stock exchanges across a wider spectrum of countries in different circumstances than possible with data only since 1950 . These data also allow us to present evidence on the association of opening these institutions with the growth of physical and human capital and TFP.

In this paper, we examine whether the opening of an exchange is associated with faster economic growth. We also examine whether these openings lead or lag any change in economic growth. More specifically, we examine whether there is a significant change in a country's growth rates of output, physical capital, human capital, or TFP after the creation of a stock exchange. Besides comparing growth before and after a stock exchange opens, we compare countries' growth rates to growth rates in all the other countries in the world for which we have data for the same period.

Our evidence provides some support for the proposition that growth in a country is higher following the creation of a stock exchange. There is some evidence that economic growth increases relative to the rest of the world after a stock exchange opens. This increase in economic growth 
primarily is an increase in the growth rate of productivity, not in the growth rate of capital. We also examine "financial deepening" - growth of a broad monetary aggregate relative to income - before and after a stock exchange opens. Our evidence suggests that financial deepening is rapid before the creation of a stock exchange and slows down subsequently, similar to the empirical evidence on this issue presented by Clayton, Jorgensen and Kavajecz (2000). This decrease in financial deepening can be explained in various ways: one way is that the growth of impersonal cash transactions precedes the growth of impersonal trades of ownership in companies; another way is that stock in firms is a substitute for banks' liabilities.

In sum, we view our findings as supportive of a story in which before a stock exchange opens, there is an increase in impersonal transactions and financial deepening that facilitates these trades. Once there is sufficient liquidity, a stock market opens and higher growth ensues. This higher economic growth occurs because the exchange increases the economy's efficiency, either the informational efficiency, the efficiency of physical capital's allocation, both, or in some other way.

This paper is organized as follows. The next section discusses the theoretical relationship between financial development and economic growth and the economics of opening stock exchanges. The succeeding section presents the data. Section four presents the empirical results and the last section presents our conclusions.

\section{ECONOMIC GROWTH AND STOCK EXCHANGES}

Besides considering the effect of a stock exchange on an economy, it is important to bear in mind the endogeneity of opening a stock exchange. In this section, we discuss the economics underlying an effect of a stock exchange on economic growth and the economics of opening exchanges. 


\section{A. Economic Growth and Financial Development}

The relationship between output and resources can be summarized by an aggregate production function which can be written

$$
Y(t)=A(t) F(K(t), H(t))
$$

where $Y(t), K(t)$ and $H(t)$ are output, physical capital and human capital at $t$ and the parameter $A(t)$ represents the level of technology, TFP, at $t$. If social marginal products equal private ones and there is perfect competition, equation (1) implies that

$$
y(t)=\alpha k(t)+(1-\alpha) h(t)+a(t)
$$

where "is capital's share of income and the lower-case letters denote the growth rate of variables per worker. The factor shares, $\alpha$ and $1-\alpha$ generally vary over time. Because our estimates are based on an assumption that such variation is relatively unimportant, we leave out time subscripts on $\alpha$ in equation (2). We can combine the growth rates of physical and human capital into aggregate input, $x(t)=\alpha k(t)+(1-\alpha) h(t)$, so that

$$
y(t)=x(t)+a(t) .
$$

The growth rate of TFP per worker, $a(t)$, in equation (3) is a residual computed from the other variables, which are observable. We use equation (3) to estimate the growth rate of TFP per worker as well as the variation in its growth over time and across countries.

A stock exchange can affect the growth rate of output by increasing the growth rate of either aggregate input per worker or TFP per worker. Financial development might well affect the growth of human capital over a longer period, but any effect on aggregate input over ten or 20 years is likely to be on the growth of physical capital. If a stock exchange increases the growth rate of physical capital by providing investors with a more desirable liability than without a stock exchange, then 
the growth rate of aggregate input, $x$, will increase. This is related to the analysis by Bencivenga and Smith (1991). ${ }^{2}$ Alternatively, as in Greenwood and Jovanovic (1990), intermediaries in general and a stock market in particular may provide investors with a payoff that is preferred and has a higher mean because intermediaries aggregate information and permit a more efficient allocation of investment. In terms of equations (2) and (3), this analysis indicates an increase in the growth of physical capital and aggregate input.

Under what circumstances can the increase in the growth rate of output be permanent? We examine the growth rates only over ten and twenty-year time intervals and it is quite possible that a transitory effect on growth will continue for even ten or twenty years. Even so, it is worthwhile to think about what is required for a permanent increase in the economy's growth rate to occur.

It is obvious that a permanent increase in the growth rate of aggregate input will increase the growth rate of output permanently, but it is less obvious why the growth rate of aggregate input would increase permanently due to the one-time opening of a stock market. As in Bencivenga and Smith (1991), it is most natural that the growth rate of physical capital increases, and with diminishing returns and typical assumptions about the rest of the economy, the growth rate of capital will eventually return to its prior growth rate. One way for the growth rates of output and physical capital to stay higher forever is if the growth rate of human capital increases, so that physical and human capital increase proportionally. One explanation for this development is the knowledge necessary to operate at the level of abstraction of a stock market, which no doubt requires a minimum level of human capital. Opening a stock exchange may be one of a continuing sequence of financial transformations that permanently increase the growth rate of output, a development that

\footnotetext{
${ }^{2}$ Their analysis explicitly is in terms of banks.
} 
can be interpreted along the lines of Knight's theory of capital which makes no distinction between physical and human capital (Knight 1944). ${ }^{3}$

A continuing increase in TFP also can permanently increase the growth rate of output, but it is less obvious why the growth rate of TFP should permanently increase due to a one-time opening of a stock market. A permanent increase in the growth rate of TFP is most plausible if the increases in TFP are associated with continuing increases in the acquisition of knowledge. It is hardly an immediate implication of opening a stock exchange, but an increase in investment in new knowledge after the introduction of a stock exchange is possible. The introduction of a stock market can affect long run growth if TFP growth is a function of the existing level of human capital (Nelson and Phelps 1966). Alternatively, the stock market may eventually increase investment and therefore output growth.

In any case, the ten-year and twenty-year growth rates that we use below will show any effect of a stock exchange on the level of income if the effect on the level is large relative to the variance of the growth rates, even if the increase in growth is not permanent. We look only at growth rates because any analysis that examines the relationship between the level of income and opening a stock exchange risks finding the effect of higher income on the demand for liquid assets and a stock exchange, and then misinterpreting the effect as one of the stock exchange on income.

\section{B. Opening A Stock Exchange}

Even though it is seldom addressed, the endogeneity of opening a stock exchange is an important issue. The opening a stock exchange is not exogenous relative to developments in the

\footnotetext{
${ }^{3}$ In terms of modern growth theory, production would have an $A k$ form, where aggregate input is indicated by the term $k$ in $A k$. Barro and Sala-i-Martin (1995, pp. 144-46) show how the details work out, and Jones and Manuelli (1990) provide a general analysis.
} 
economy, whether it be the New York Stock Exchange or the Tehran Stock Exchange. A stock exchange is formed to lower the cost of trading ownership rights in firms, and it is opened at one date and not others for a good reason, presumably because opening at a particular date maximizes the returns to the exchange's organizers. In some cases, the date is entirely endogenous, as in the creation of the New York Stock Exchange in 1792, and in some cases it is partly exogenous, as in the re-opening of the Warsaw Stock Exchange in 1991 after the fall of the Soviet empire.

The increase in income in an economy associated with opening and operating a stock exchange, if it could be captured by the organizers, is reason enough to open a stock exchange, whether the increased income occurs because of lower transactions costs, improvements in information or for other reasons. Greenwood and Jovanovic's (1990) model is one in which the development of a financial intermediary such as a stock exchange is endogenous. In their model, there are fixed costs involved in the organization of the intermediary and proportional costs in the operation of the intermediary, with three benefits of establishing an exchange. These three benefits are diversification of projects' idiosyncratic risk by trades of assets; improved intertemporal substitution of consumption; and improved allocation of investment due to the information aggregation by the intermediary. Because any agent can be an intermediary, the intermediary can earn no rents in equilibrium. As the level of capital and income increases, the gains from the intermediary increase and eventually some agents participate in the intermediary. As their wealth increases, more agents participate, the return to capital increases and the allocation of investment improves. The level of saving may actually fall, but the improved allocation of investment raises the growth rate of income in the equilibrium with all agents participating in the intermediary compared 
to the equilibrium without an intermediary. This higher growth can continue forever because the model has $A k$ production.

Greenwood and Jovanovic's model is a highly stylized characterization of the organization of exchanges and, as they note (Greenwood and Jovanovic 1990, pp. 1084-85), is general enough to include banks and similar financial intermediaries, stock exchanges and other financial markets. The organization of exchanges is a substantial literature in itself and perhaps the most initially striking deviation of Greenwood and Jovanovic's analysis from analyses of exchanges is the assumption of perfect competition in their model and the general consensus that monopoly rents are important for understanding exchanges. ${ }^{4}$ There is no reason to think, though, that the implications of their analysis would be overturned; after all, stock exchanges are as unlikely to be able to extract all the rents created by their operation as are other firms.

In addition to the actual organization of exchanges, the legal environment is important for an exchange and can prevent their formation. Because we do not examine the determinants of exchanges opening, we do not pursue this point other than to note its importance.

\section{THE DATA}

Our analysis uses a newly available set of data that covers longer time periods for more countries than data previously used for growth analysis (Baier, Dwyer and Tamura 2002, 2003). This set of data contains per worker values of output, physical capital and human capital for 145 countries for an average of 57 years, and the data extend backward beyond 1900 for 24 of the countries. For each of these countries, we calculate output per worker, physical capital per worker, human capital per worker, and TFP per worker. To make it less likely that a relatively high frequency phenomena

\footnotetext{
${ }^{4}$ See, for example, Pirrong $(1999,2000)$.
} 
such as business cycles affect the empirical analysis, a single growth observation should cover at least ten years or, more likely, twenty years. For this paper, we compare the country's growth rate over periods of ten to twenty years before and after the exchanges open.

For comparison, the heavily used dataset provided by Summers and Heston (1988, 1991, 1998) is a large cross section with limited time-series information. Summers and Heston's dataset contains information on 152 countries but does not include information on any country prior to 1950. Their dataset also has another important deficiency: it does not contain information on human capital. This means that the dataset cannot be used to calculate total factor productivity corrected for human capital growth unless combined with Barro and Lee's (1993) estimates of education, which start in 1960 .

\section{A. Growth Accounting Framework}

We examine the association of the creation of stock exchanges with the growth of output and with the growth of physical and human capital and total factor productivity (TFP). The introduction of a stock exchange can result in a more efficient allocation of factors of production, which would show up as higher TFP growth for some period. The creation of a stock market also can raise the marginal product of capital and lead to more capital deepening, which would be reflected in faster growth of physical capital after the creation of a stock exchange. By construction, if neither aggregate input nor TFP is affected, output cannot be affected either.

The growth rate of TFP per worker in equation (3) need not represent only technological change and may not represent technological change at all. Deviations of social and private marginal products can but need not result in terms included in TFP growth (Barro 1999), as can increasing returns. In addition, changes in property rights and economic regime can result in apparent TFP 
changes, although it is not clear whether such changes should be interpreted as changes in the difference between the social and private marginal products. Measurement errors in output and physical and human capital or changes in the efficiency of the allocation of inputs can appear in TFP growth. In short, there are many possible explanations of changes in TFP per worker. If the creation of financial institutions is the only change, then TFP growth will reflect any changes in the allocation of human and physical capital in response to the creation of the financial institutions.

The data are not available annually in the early years. The data generally are available approximately every ten years, although some of the skips between observations are longer around wars and other disruptive events. As a result, we compute growth rates for one or two periods before and after a stock market opens, with a period being roughly ten years. The periods that we use are the first period before the exchange opens and the first period after the exchange opens, which need not be the ten years immediately before or the ten years immediately after the stock exchange opens. ${ }^{5}$ Suppose that we have data for a country from 1860 to 1900 on the years divisible by ten. If the stock exchange opens in 1880, then the one-period growth rate before the stock exchange opens is the growth rate for 1870 to 1880 and the one-period growth rate after the stock exchange opens is the growth rate for 1880 to 1890 . If the stock exchange opens in any year from 1881 to 1889 , the growth rate before the stock exchange opens still is the growth rate for 1870 to 1880 but the growth rate after the stock opens is for 1890 to 1900 . We use this period after the exchange opens because a growth rate spanning the opening of the stock exchange is not a growth rate before the exchange opens or a growth rate after the stock exchange opens.

\footnotetext{
${ }^{5}$ By requiring data for ten or twenty years before and after the opening of a stock market, our empirical analysis excludes countries that became independent and soon thereafter opened a stock exchange. These countries do not have data on output and investment before they are independent, which is just as well, because their growth performance is likely to confound the effects of financial markets and independence.
} 
Our analysis focuses on the growth rates of output and inputs relative to the labor force. For simplicity, we often will refer to, for example, output per worker by which we mean output per member of the labor force. Using output per worker instead of output per person simplifies our empirical analysis with no obvious loss in the informativeness of that analysis.

\section{B. Dates for Opening of Institutions}

The dates for the openings of stock exchanges primarily come from the two volume set by Sheimo (1999). If the opening data is not listed for an exchange, the next source searched was the website for the stock exchange. Additional dates for the opening of stock exchanges come from other Internet sources. ${ }^{6}$ Table 1 shows the stock exchanges included in our analysis and the dates at which they open.

There are 32 stock markets for which we can measure the growth rate of the economy for one period before and one period after the exchange opens. Of these 32 countries, ten have data that permit us to measure growth two periods before and two periods after a stock exchange opens. To increase the number of observations above ten without losing the advantage of examining two periods after an exchange opens, we also measure growth one period before and two periods after an exchange opens. We have these data for 18 countries. These stock exchanges cover most of regions in the world and span 129 years. These countries do not include many recent openings of stock exchanges in Eastern Europe because these stock exchanges opened after 1990 and we do not observe them for even one period after the exchange opens. They also do not include openings of stock exchanges when countries become independent because such countries typically do not have data on output, capital and education for the colonial period. We exclude Iran from the tables in the

\footnotetext{
${ }^{6}$ Most of the sites can be accessed from the following three websites: http://www.escapeartist.com/stock/markets.htm, http://www.finix.at/fin/selinks.html, and http://www.tdd.lt/slnews/Stock_Exchanges/Stock.Exchanges.htm
} 
text and present them in an Appendix because Iran has a very substantial effect on some results and we think that excluding Iran from the measured effects of a stock exchange is more informative. ${ }^{7}$

\section{Measures of Effect}

There are several ways to measure whether growth has increased following the opening of a financial institution. We measure the possible effect three ways, each relative to a base growth rate. The comparisons are: growth after the institution opens relative to growth before it opens; growth after the institution opens relative to growth in the rest of the world; and the change in growth relative to the change in growth in the rest of the world.

All of these comparisons are measures of the growth rate of the economy relative to plausible base growth rates. The growth rate of income after a financial institution is created can be written

$$
z_{i, t}=\mathrm{E} z_{i, t-1}+\varepsilon_{i, t}
$$

where $z_{i, t}$ is the growth rate of real income, physical capital, human capital or TFP after the exchange is created, $\mathrm{E} z_{i, t}$ is the base, or expected, growth rate and $\mathrm{g}_{, \mathrm{t}}$ is a zero-mean error term. The term $\mathrm{E} z_{i, t}$ represents the base level of growth. If there is no effect of creating a financial institution, then there is no expected change in growth rate relative to its expected level and

$$
\mathrm{E}\left(z_{i, t}-\mathrm{E} z_{i, t-1}\right)=0
$$

Alternatively, if there is an effect of creating a financial institution, then

$$
\mathrm{E}\left(z_{i, t}-\mathrm{E} z_{i, t-1}\right)=\mu \neq 0
$$

\footnotetext{
${ }^{7}$ We observe Iran for two periods before and after the stock exchange opens, but the Iranian revolution and a substantial negative growth rate of output follow the opening of the stock market. We interpret Iran as an outlier that distorts the numerical results. The Iranian revolution could be interpreted as one possible consequence of introducing a stock market. Our conclusions generally are unaffected if Iran is included in these comparisons, although the point estimates and their statistical significance are affected.
} 
where the constant : indicates the nonzero effect of introducing the financial institution. The key issue is determining the expected or base growth rate.

A simple measure of the base growth rate is the growth before the creation of the stock exchange: $z_{i, t-1}$. If there were no effect of the stock exchange, the growth rate before and after creating the institution would be the same on average and

$$
\mathrm{E}\left(z_{i, t}-z_{i, t-1}\right)=0
$$

A nonzero mean would indicate an effect of the institution.

Another measure of the base growth rate is the growth rate in other countries: $z_{i, t}^{o}$. In this case, no effect of the stock exchange would imply that there is no difference between the growth rate in the country with a new exchange and other countries and

$$
\mathrm{E}\left(z_{i, t}-z_{i, t}^{o}\right)=0
$$

In our empirical analysis, we measure the growth rate in other countries by the growth rate in the rest of the world, and a nonzero mean indicates an effect of the exchange's opening.

The third measure of the base growth rate is based on the change in the growth rate in a country relative to the growth rate in other countries. Let $\Delta z_{i, t}=z_{i, t}-z_{i, t-1}$ be the change in the growth rate in a country and $\Delta z_{i, t}^{o}=z_{i, t}^{o}-z_{i, t-1}^{o}$ be the change in the rest of the world. With these measures of the change in the growth rate, no effect of opening a stock exchange implies

$$
\mathrm{E}\left(\Delta z_{i, t}-\Delta z_{i, t}^{o}\right)=0
$$

If a new stock exchange increases the growth rate in a country, then the change in the growth rate in country $i$ would be greater than in other countries and there would be a nonzero mean difference in the changes in the growth rates. 
In addition to examining the data for mean changes, the statistical analysis also includes the fraction of countries with increases relative to the base growth rates. If there is an increase in average growth and more than 50 percent of the countries experienced higher growth after an exchange opens, this is additional evidence that higher growth generally follows the opening of a stock exchange.

\section{The EFFECTS OF OPENING A STOCK EXChANGES}

In this section, we examine whether there is a measurable increase in the growth rates of output and inputs when a stock exchange opens. We also examine whether there is any association with financial deepening.

\section{A. Economic Growth}

First, we examine the effect of introducing a stock market over two periods. Then we examine the data for shorter periods which makes it possible to have more observations. Table 2 shows comparisons of the growth rates two periods before and after a stock exchange opens. There are three comparisons of the countries' growth rates after a stock exchange opens relative to a base growth rate. The first column shows the country's growth rate after a stock exchange opens relative to the growth rate before the exchange is created, the second column shows the growth after a stock exchange opens relative to the growth in the rest of the world for the same period, and the third column shows the change in the growth rate in the country relative to the change in the rest of the world for the same period. The first column of Table 2 shows that the growth rate in a country is essentially the same before and after a stock exchange opens. The average change in the growth rate is 0.28 percent per year, which is far less than the standard deviation of 0.82 percent. Furthermore, only 44 percent of the countries have higher growth after a stock exchange opens, a point estimate 
that is less than one half although not statistically different from one half given the standard deviation of 17 percent. $^{8}$ The very large standard deviation of mean output growth means that an extraordinary average increase in the growth rate of output of 1.64 percent per year over a twentyyear period would be necessary to find a statistically significant increase. The measured mean growth rates of the capital stock and TFP also are low relative to their standard deviations. Interestingly, the increase in the growth of human capital is statistically significant, but we are not inclined to put much credence in that statistic given the lack of any evidence of an effect elsewhere. ${ }^{9}$ The comparisons to the rest of the world, which have lower standard deviations, are more consistent with an effect of opening a stock exchange.

The second and third columns of Table 2 shows that the growth rate of output on average is 1.04 percent higher after a stock exchange is created relative to growth in the rest of the world, and this increase is large relative to the standard deviation of 0.43 percent per year. The change in the growth rate of output also is large relative to the rest of the world, 1.33 percent per year and also is large relative to its standard deviation. Two-thirds of the countries with a new stock exchange have a higher growth rate of output than in the rest of the world for two periods afterward and 78 percent of them have an increase in their growth rate relative to the rest of the world. These are large estimated effects. What are the sources?

Table 2 shows that the growth rate of TFP is the primary source of the relatively faster growth of output. After a stock exchange opens in a country, the growth rate of TFP on average is

\footnotetext{
${ }^{8}$ The standard deviation is based on the binomial distribution.

${ }^{9}$ By definition, the average growth rate of output equals the average growth rate of output implied by the growth of physical and human capital and TFP. Given the correlations among the variables, the standard deviation of any one of the four growth rates is implied by the other three. Rather than give primacy to three of the four statistics, our strategy is to discuss all four t-statistics and take note of the dependence when it is pertinent.
} 
0.60 percent per year higher than in the rest of the world. The change in the growth rate relative to the rest of the world is 0.86 percent per year, showing that the growth rate increases relative to the rest of the world. This relative change in average growth rate of 0.86 percent per year has a t-statistic of 2.39 and a one-sided p-value of 2.2 percent, and the TFP growth rate of 0.60 percent per year has a t-statistic of 1.62 and a one-sided p-value of 7.2 percent. While the point estimate of the increase in the growth rate of physical capital is 1.04 , this is not especially large relative to standard deviation of 0.81 and its contribution to output growth is capital's share of income, one third, times 1.04. The point estimates indicate that TFP accounts for 0.60 percent per year of the output growth of 1.04 percent per year, and growth of physical capital accounts for about 0.34 percent per year.

Figure 1 shows the data on output growth that underlies Table 2. The vertical axis is the country's growth rate or change in growth rate and the horizontal axis is the base or expected growth rate or change in growth rate. If growth in a country is higher than the base rate, then the point lies above the line, and conversely for slower growth. Figure 1 shows what the standard deviations in Table 2 suggest: There is extraordinary variability in growth rates across countries. The first panel shows that, while all the countries underlying Table 2 have positive growth rates for two periods before and after a stock exchange opens, the increases are dramatic for some and the falls are not trivial for others such as Costa Rica. The second panel shows that the growth rates in countries after stock exchanges open are high relative to the rest of the world in the same periods, and the third panel shows that the changes in output growth, even when quite negative as in Costa Rica, occur in periods in which the change in average output growth in the rest of the world is negative as well. In sum, world output growth has a high correlation with the countries' output growth rates and the standard deviations fall when developments in the rest of the world are considered. 
While we find these results informative, only nine countries are the basis of these statistics. Do the results hold up when more countries are added? Short of waiting twenty years or creating historical data to make it possible to add countries, we can add more countries to the analysis by shortening the time interval over which comparisons are made.

First, we shorten the base time interval but estimate the effects over two periods after a stock exchange opens. This increases the number of observations to seventeen. Table 3 is the same as Table 2 except that the base growth rates are for one period rather than two; the effect still is measured over two period after a stock exchange opens. Overall, we interpret these results as being similar to those in Table 2. As would be expected, the standard deviations generally increase compared to Table 2. The first column provides no evidence that growth increases after a stock exchange opens compared to growth before the exchange opens. In fact, all the point estimates of the changes in growth are negative. The point estimates in Table 2, though, provide no evidence of higher growth after a stock exchange opens with prior growth as the base growth rate. The second column shows that, after a stock exchange opens, the growth rates of output and TFP are 0.58 and 0.50 percent per year higher than in the rest of the world, differences that are similar in terms of their overall implications for the effects of stock markets, even if they are smaller in magnitude than the comparable figures in Table 2 and not statistically significant. The third column shows that the average changes in the growth rate of output and TFP relative to the rest of the world are 0.28 and 1.11 percent per year, and while 0.28 percent per year is far from statistically significant with its standard deviation of 0.67 percent per year, the change in the growth rate of TFP has a t-value of 1.79 with a one-sided p-value of 4.6 percent. 
Table 4 presents a similar analysis of growth rates using one period before and one period after a stock exchange opens. The statistics in this table are based on 31 countries. As in the tables above, examining each country in isolation would suggest no effect. In fact, the point estimates suggest that countries grow slower after an exchange opens than before an exchange opens, with the average growth rates of output, physical and human capital and TFP all falling. Such a conclusion, besides being startling, would be misleading. The second column shows that the average country has output growth 1.14 percent per year faster than the rest of the world after a stock exchange opens, with a t-statistic of 1.84 and a one-sided p-value of 3.8 percent. These countries also have faster growth of physical capital, human capital and TFP, although the 0.86 percent higher growth of TFP accounts for 75 percent of the higher output growth. The third column shows that the change in output growth relative to the change in the rest of the world also is positive, although a smaller 0.27 percent per year, and the relative change in TFP growth is a more substantial 0.72 percent per year. The decrease in the growth rate of physical capital relative to the rest of the world of 0.63 percent per year may just reflect random variation, a conclusion quite consistent with the standard deviation of 0.87 , or it may reflect a temporary decrease in capital growth due to an increase in consumption associated with an increase in wealth at the stock exchange's openings. While not enough by themselves to be convincing that countries grow faster than the rest of the world after a stock exchange opens, these statistics in Table 4 are consistent with such a conclusion.

Overall, we conclude that the evidence in Tables 2, 3, and 4 indicates that countries in which stock exchanges open grow faster after the exchange opens. This is most evident in Table 2, although all of the tables show higher growth of output relative to the rest of the world after an exchange opens and an increase in growth relative to the rest of the world. Furthermore, these 
growth rates primarily are associated with like changes in TFP. How then can one explain the negligible or negative changes in growth in the countries themselves? Algebraically, the change in growth in the rest of the world has fallen when a stock exchange opens, which is most plausibly a matter of happenstance.

\section{B. Financial Deepening}

Are these results for stock markets reflected in financial deepening? As is conventional, we measure financial deepening by the growth of broad monetary aggregates - M2, quasi-money and M3 - relative to income. We do not have data on these assets before $1960 .^{10}$

Table 5 presents some simple evidence on this issue for the opening of stock exchanges for one period. Table 5 shows average financial deepening after the opening of a stock exchange relative to financial deepening before the opening of a stock exchange, relative to financial deepening in the rest of the world, and the change in financial deepening relative to the change in the rest of the world. Because the countries for which we have data on a broad monetary aggregate are quite limited relative to the countries for which we have data on output and input, we also present averages for output, physical and human capital and TFP growth to examine whether these countries are atypical. The average growth rates of output, physical and human capital and TFP are comparable to those in Table 4. The picture is broadly similar, perhaps the major difference being higher TFP growth relative to the rest of the world and a larger increase in Table 5 than in Table 4.

Financial deepening falls after a stock exchange opens. We focus on the results for M3, typically used to measure financial deepening, since the other results are broadly similar. The average fall in financial deepening measured by M3 growth relative to income is substantial: -2.59

\footnotetext{
${ }^{10}$ Data on broad monetary aggregates are from the World Development Report and begin in 1960.
} 
percent per year, although the standard deviation is a relatively high 2.18 percent per year. After a stock exchange opens, financial deepening averages about 1.45 percent higher than in the rest of world. Nonetheless, the change in the growth of financial deepening is -1.64 percent per year relative to the rest of the world. The change in the typical country's financial deepening is quite negative relative to the rest of the world after a stock exchange opens. Even if financial deepening is proceeding at a relatively rapid clip of 1.45 percent per year faster than in the rest of the world on average after an exchange opens, it was quite a bit faster relative to the rest of the world before the exchange: subtraction reveals that financial deepening before a stock exchange opens is about 3.09 percent per year higher than in the rest of the world. This suggests that financial deepening precedes the creation of a stock exchange and slows down substantially when it opens, a result similar to the one suggested by the evidence in Clayton, Jorgensen and Kavajecz (2000).

Why would such a decrease in financial deepening occur when a stock exchange opens? This decrease in financial deepening may be associated with a slowdown in the growth of households' assets issued by banks when they can acquire exchange-traded assets, an interpretation consistent with the analysis in Bencivenga and Smith (1991). A more general interpretation is that financial deepening is associated with the development of impersonal transactions in the economy. Stock exchanges facilitate impersonal trades of stock in companies, and growth of impersonal trade in general precedes impersonal trade of stock in companies.

\section{CONCLUSION}

Does the creation of stock exchanges increase economic growth? Our evidence indicates that countries grow faster relative to the rest of the world after a stock exchange opens. The evidence 
also indicates that a more efficient allocation of resources rather than more capital accumulation is the primary channel through which a stock exchange affects output growth.

Is a stock exchange a causal factor in growth? There are two ways of thinking about this question. One way would be whether it is causal in the sense that it is exogenous to growth. The answer to this must be that most if not all of these stock exchanges were opened because of an expectation that they would be profitable ventures; they clearly are endogenous. Nonetheless, ancillary legal developments are important for opening a stock exchange, operating it and making the anticipated positive return. Our evidence suggests that such legal developments can facilitate growth by easing the way for a stock market. A second way of thinking about the causal role of a stock exchange is whether prohibiting a stock exchange can reduce growth. Our evidence points in the direction of saying that suppressing a stock exchange or impeding its operation is a good way to reduce economic growth. 


\section{Acknowledgments}

We thank Scott Hein for helpful comments. Shalini Patel provided her usual careful research assistance. Earlier versions of this paper were presented at the conference on Finance and Growth at the Federal Reserve Bank of Atlanta and a Banking Workshop at the Bank of Finland. We thank the participants at both conferences for many helpful comments and James Lothian and Paul Wachtel for their written comments. The views expressed here are the authors' and not necessarily those of the Federal Reserve Bank of Atlanta or the Federal Reserve System. Any errors are the authors' responsibility. 


\section{References}

Atje, Raymond, and Boyan Jovanovic. 1993. "Stock Markets and Development." European Economic Review 37 (April), 632-40.

Baier, Scott L., Gerald P. Dwyer, Jr., and Robert Tamura. 2003. "Modern Economic Growth and Stagnation.” Federal Reserve Bank of Atlanta Economic Review 88 (Third Quarter), 45-62.

Baier, Scott L., Gerald P. Dwyer, Jr., and Robert Tamura. 2002. "How Important Are Capital and Total Factor Productivity for Economic Growth?” Unpublished paper, Federal Reserve Bank of Atlanta.

Barro, Robert J. 1999. “Notes on Growth Accounting.” Journal of Economic Growth 4 (June), 11937.

Barro, Robert J., and Jong-Wha Lee. 1993. "International Comparisons of Educational Attainment." Journal of Monetary Economics 32 (December), 363-94.

Barro, Robert J., and Xavier Sala-i-Martin. 1995. Economic Growth. Cambridge: The MIT Press. 1999 reprint.

Bekaert, Geert, Campbell R. Harvey, and Christian T. Lundblad 2003. "Equity Market Liberalization in Emerging Markets.” Journal of Financial Research 26 (Fall), 275-99.

Bencivenga, Valerie, and Bruce D. Smith.1991. "Financial Intermediation and Endogenous Growth." 58 Review of Economic Studies. (April), 195-209.

Clayton, Matthew J., Bjorn N. Jorgensen and Kenneth A. Kavajecz. 2000. "On the Formation and Structure of International Exchanges.” Unpublished paper, New York University.

Greenwood, Jeremy, and Boyan Jovanovic. 1990. "Financial Development, Growth, and the Distribution of Income.” Journal of Political Economy 98 (October), 1076-1107.

Jones, Larry E., and Rodolfo Manuelli. 1990. “A Convex Model of Equilibrium Growth: Theory and Policy Implications.” Journal of Political Economy (October), 1008-38.

King, Robert G., and Ross Levine. 1993.'Finance, Entrepeneurship, and Growth.” Journal of Monetary Economics 32 (December), 513-42.

Knight, Frank H. 1944. "Diminishing Returns From Investment.” Journal of Political Economy 52 (March), 26-47.

Levine, Ross. 2002. "More on Finance and Growth.” Unpublished paper, University of Minnesota. 
Nelson, Richard R. and Edmund S. Phelps. 1966. "Investment in Humans, Technological Diffusion, and Economic Growth." The American Economic Review 56, No. 1/2 (March), 69-75.

North, Douglass C. 1988. "Institutions, Economic Growth and Freedom: An Historical Introduction." In Freedom, Democracy and Economic Welfare: Proceedings of an International Symposium. Vancouver: Fraser Institute.

Pirrong, Craig. 1999. "The Industrial Organization of Financial Exchanges: Theory and Evidence." Journal of Financial Markets 2 (November), 329-57.

Pirrong, Craig. 2000. “A Theory of Financial Exchange Organization.” Journal of Law and Economics 43 (October), 437-71.

Rousseau, Peter L., and Richard Sylla. 2001. "Financial Systems, Economic Growth, and Globalization.” NBER Working Paper 8323.

Sheimo, Michael. 1999. International Encyclopedia of the Stock Market. Two volumes. Chicago: Fitzroy Dearborn Publishers.

Summers, Robert, and Alan Heston. 1998. "Penn World Tables 5.6." http://datacenter.chass.utoronto.ca/pwt/ on February 8, 2000. , and 1991. "The Penn World Table (Mark 5): An Expanded Set of International Comparisons.” Quarterly Journal of Economics 106 (May), pp. 327-68.

, and 1988. "A New Set of International Comparisons of Real Product and Price Levels Estimates for 130 Countries, 1950-1985." Review of Income and Wealth 34 (March), pp. 1-25.

Wachtel, Paul. 2003. "How Much Do We Really Know About Finance and Growth?” Federal Reserve Bank of Atlanta Economic Review 88 (First Quarter), 33-47.

World Bank. 2000. World Development Report 2000/2001. Oxford: Oxford University Press. 
Table 1

STOCK MARKeT OPENING DATES

Countries with Output and Capital data One Period Before and After

\begin{tabular}{|c|c|}
\hline COUNTRY & OPEN DATE \\
\hline Australia $^{a}$ & 1871 \\
\hline Brazil $^{\mathrm{a}, \mathrm{b}}$ & 1890 \\
\hline Belgium $^{\mathrm{a}, \mathrm{b}}$ & 1901 \\
\hline Venezuela $^{\mathrm{a}}$ & 1947 \\
\hline South Korea ${ }^{a, b}$ & 1948 \\
\hline Taiwan ${ }^{\mathrm{a}, \mathrm{b}}$ & 1960 \\
\hline El Salvador ${ }^{\mathrm{a}}$ & 1964 \\
\hline Jamaica $^{\mathrm{a}}$ & 1968 \\
\hline Tunisia $^{a}$ & 1969 \\
\hline $\operatorname{Iran}^{\mathrm{a}, \mathrm{b}}$ & 1971 \\
\hline Singapore $^{\mathrm{a}}$ & 1973 \\
\hline Thailand $^{\mathrm{a}, \mathrm{b}}$ & 1975 \\
\hline Costa Rica ${ }^{a, b}$ & 1976 \\
\hline Ivory Coast $^{\mathrm{a}}$ & 1976 \\
\hline Portugal $^{\mathrm{a}, \mathrm{b}}$ & 1976 \\
\hline Switzerland ${ }^{\mathrm{a}, \mathrm{b}}$ & 1976 \\
\hline Indonesia ${ }^{\mathrm{a}, \mathrm{b}}$ & 1977 \\
\hline Jordan $^{\mathrm{a}}$ & 1978 \\
\hline Togo & 1981 \\
\hline Trinidad & 1981 \\
\hline Namibia & 1985 \\
\hline Guatemala & 1987 \\
\hline Bolivia & 1989 \\
\hline Botswana & 1989 \\
\hline Ghana & 1989 \\
\hline Mauritius & 1989 \\
\hline Yugoslovia & 1989 \\
\hline China & 1990 \\
\hline Honduras & 1990 \\
\hline Hungary & 1990 \\
\hline Panama & 1990 \\
\hline Romania & 1990 \\
\hline
\end{tabular}

${ }^{a}$ Data are available for the country for one period before and two periods after the opening of the stock market.

${ }^{\mathrm{b}}$ Data are available for the country for two periods before and after the opening of the stock market 


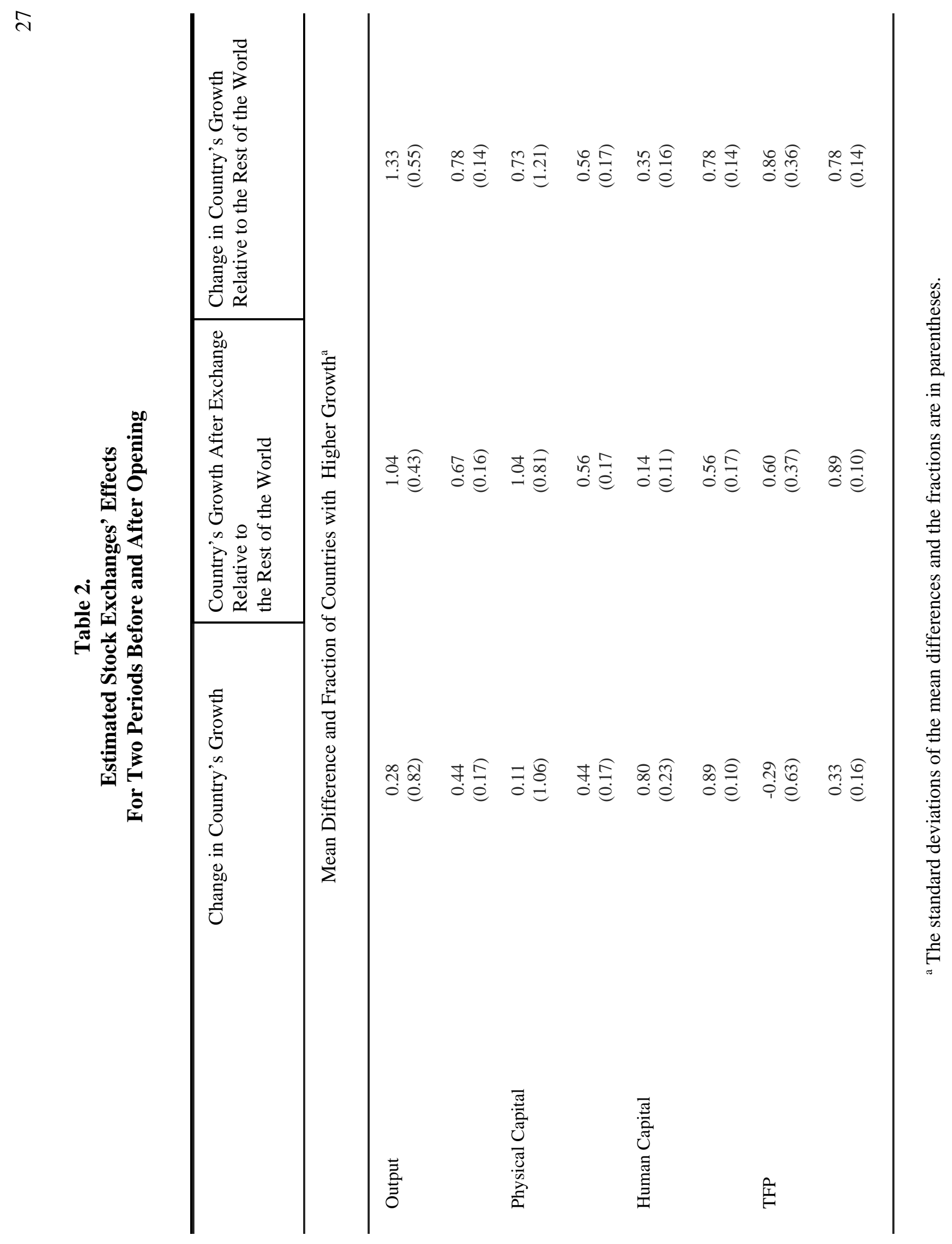




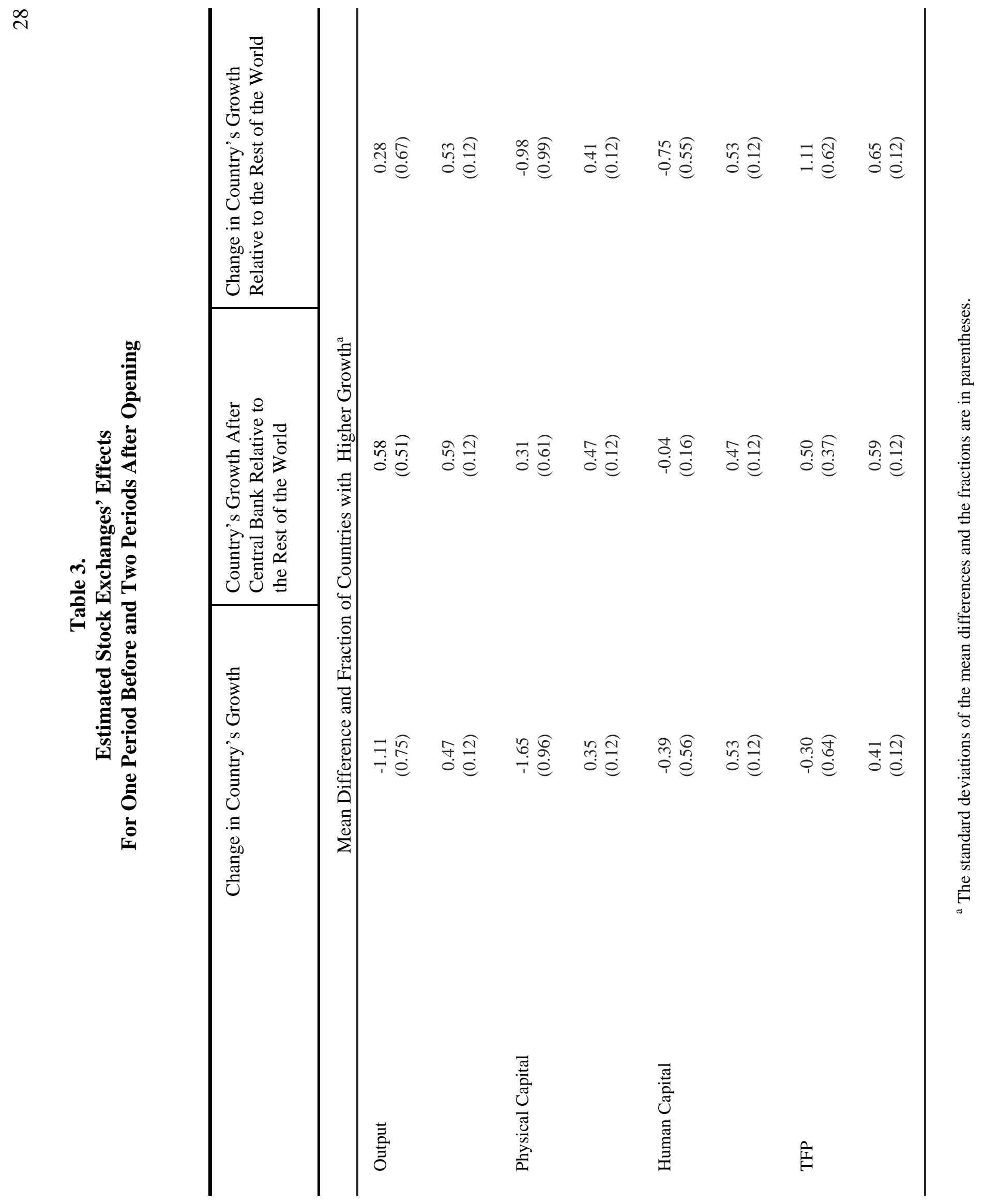




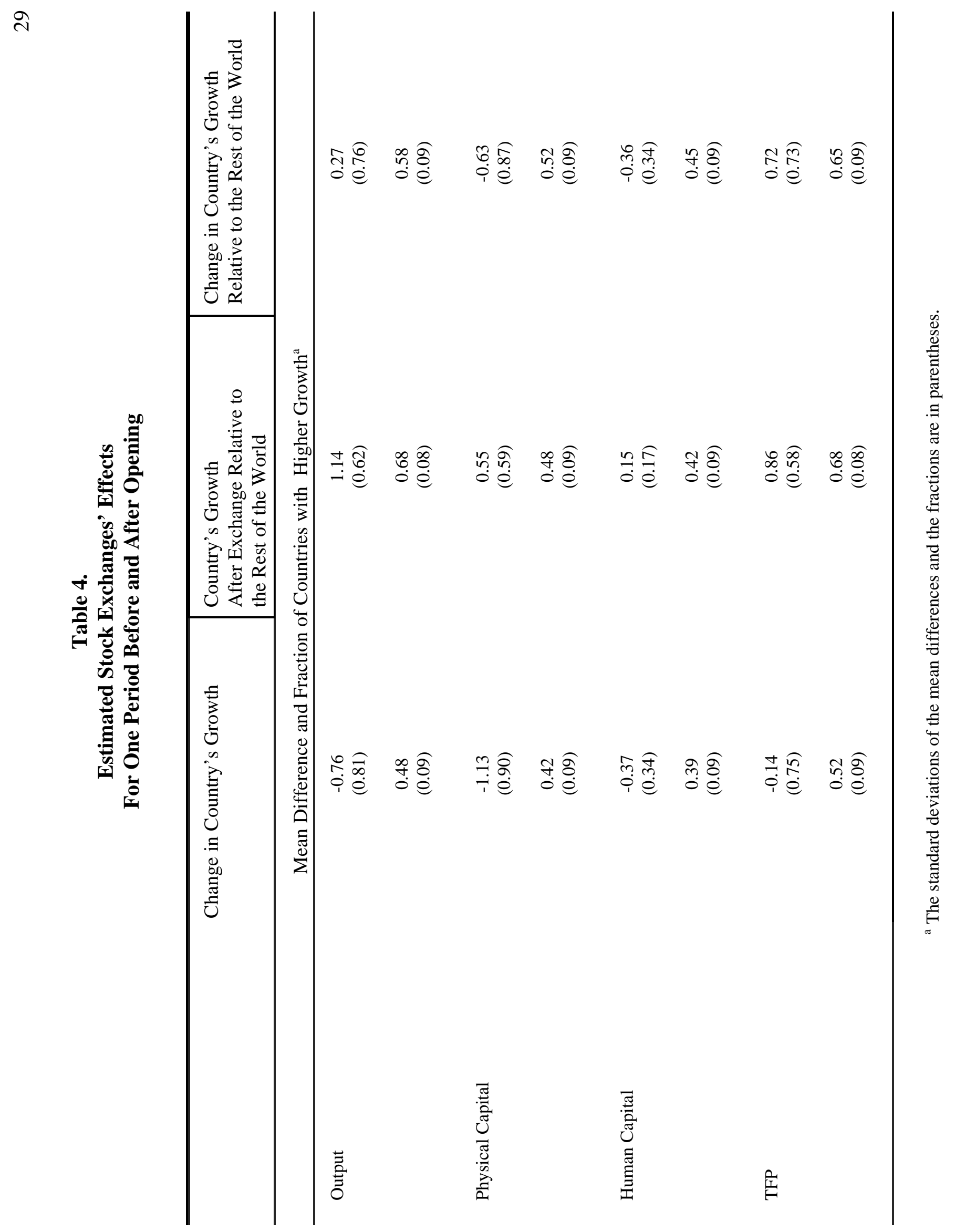


요

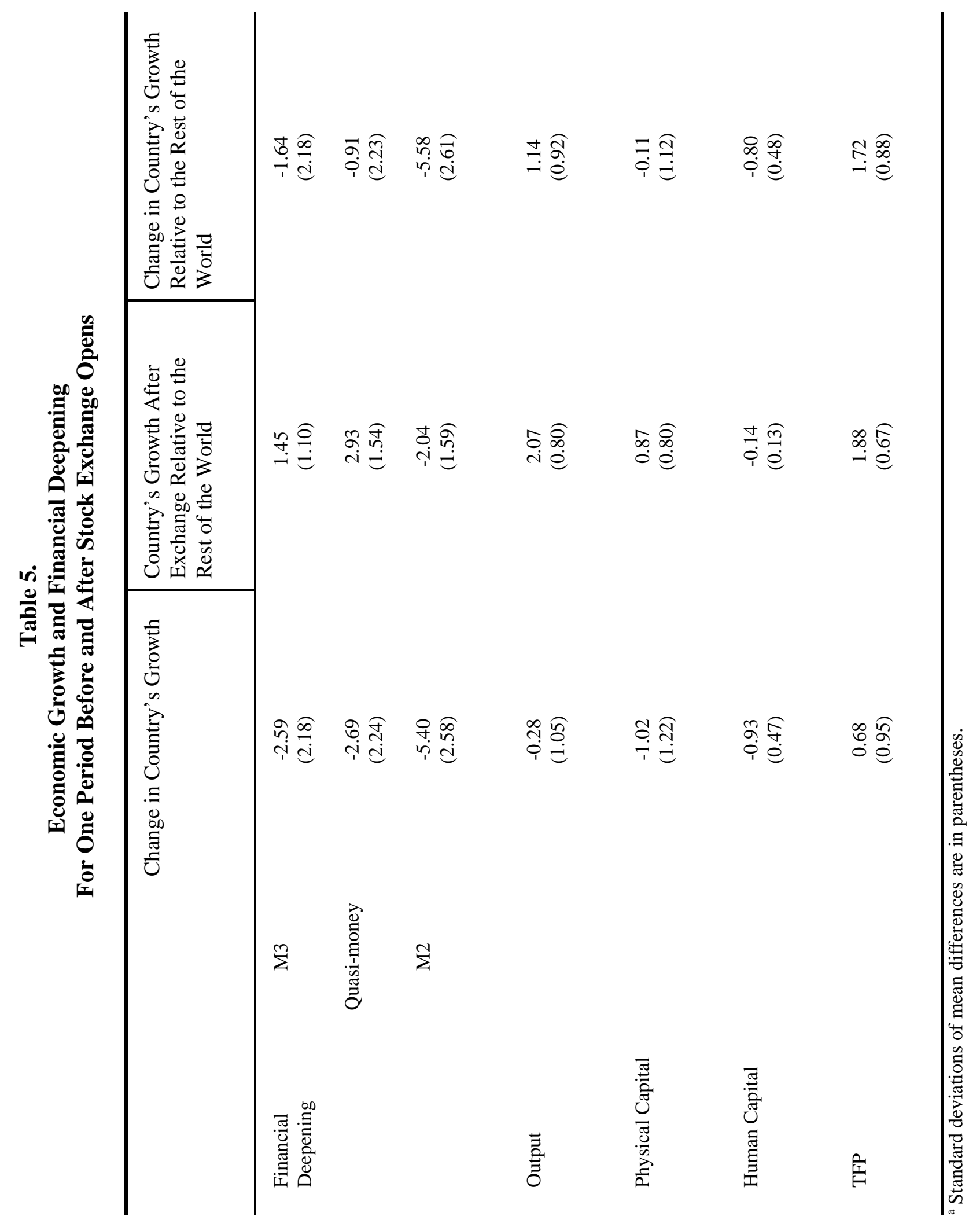


$\bar{m}$

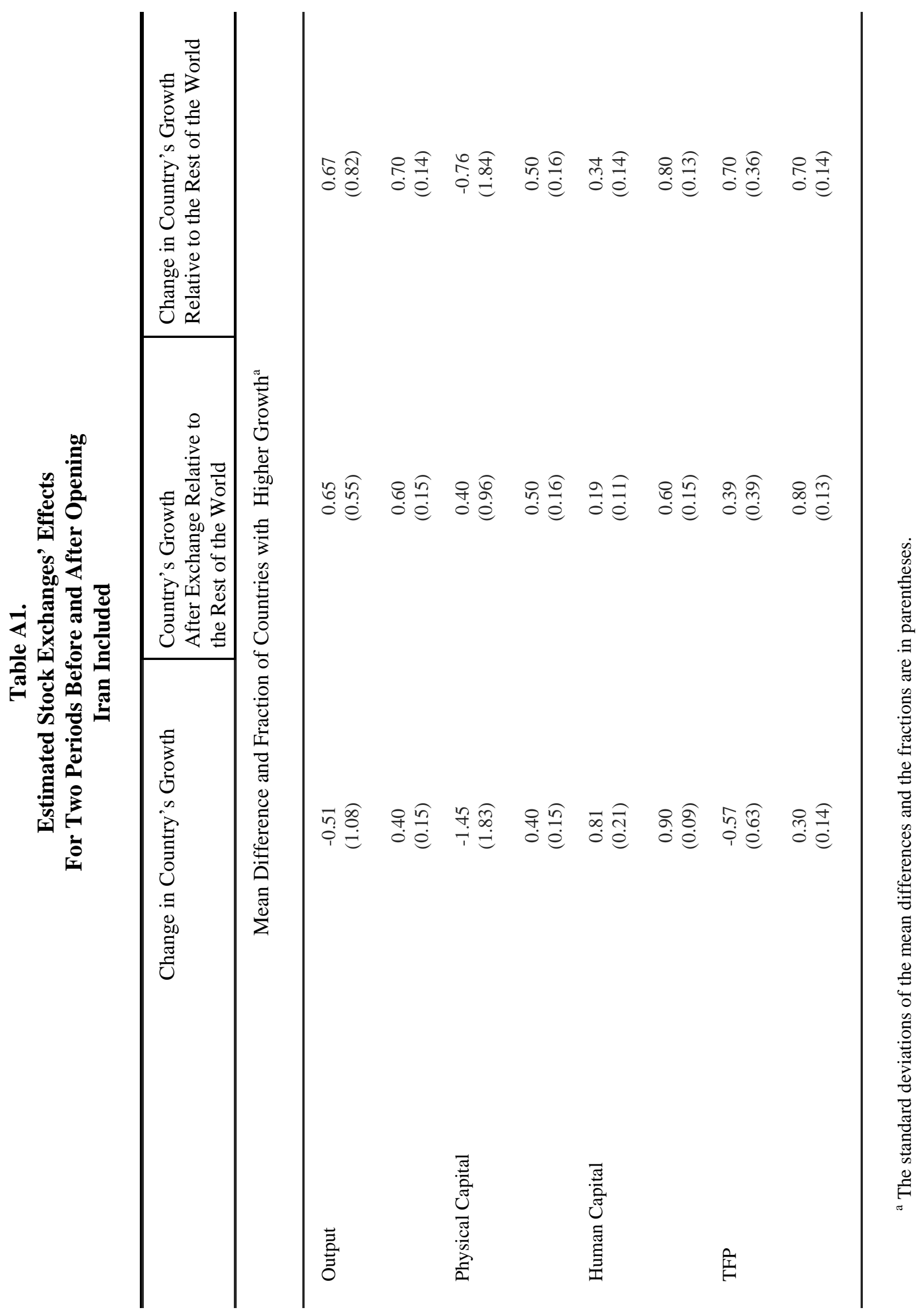


त)

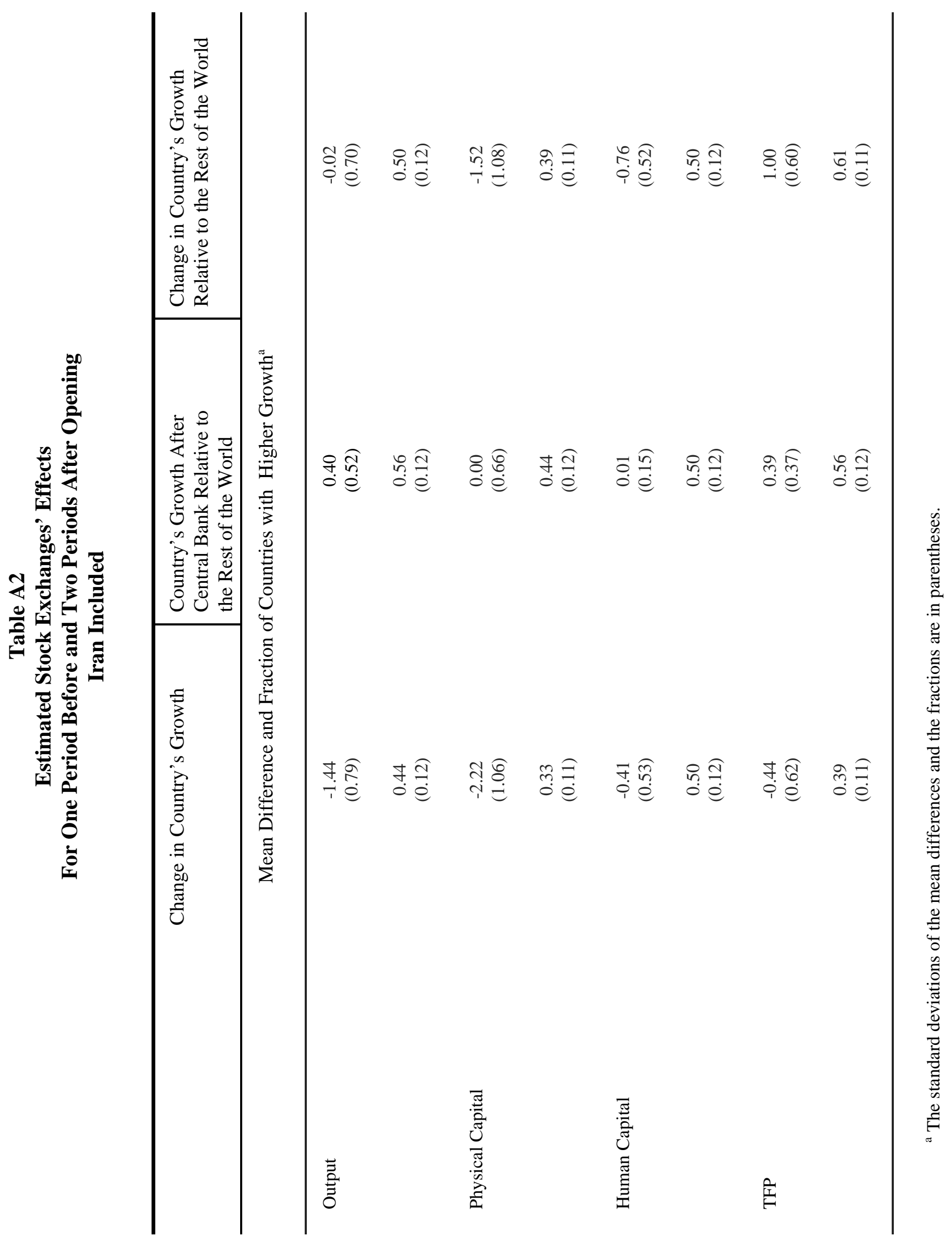


$m$

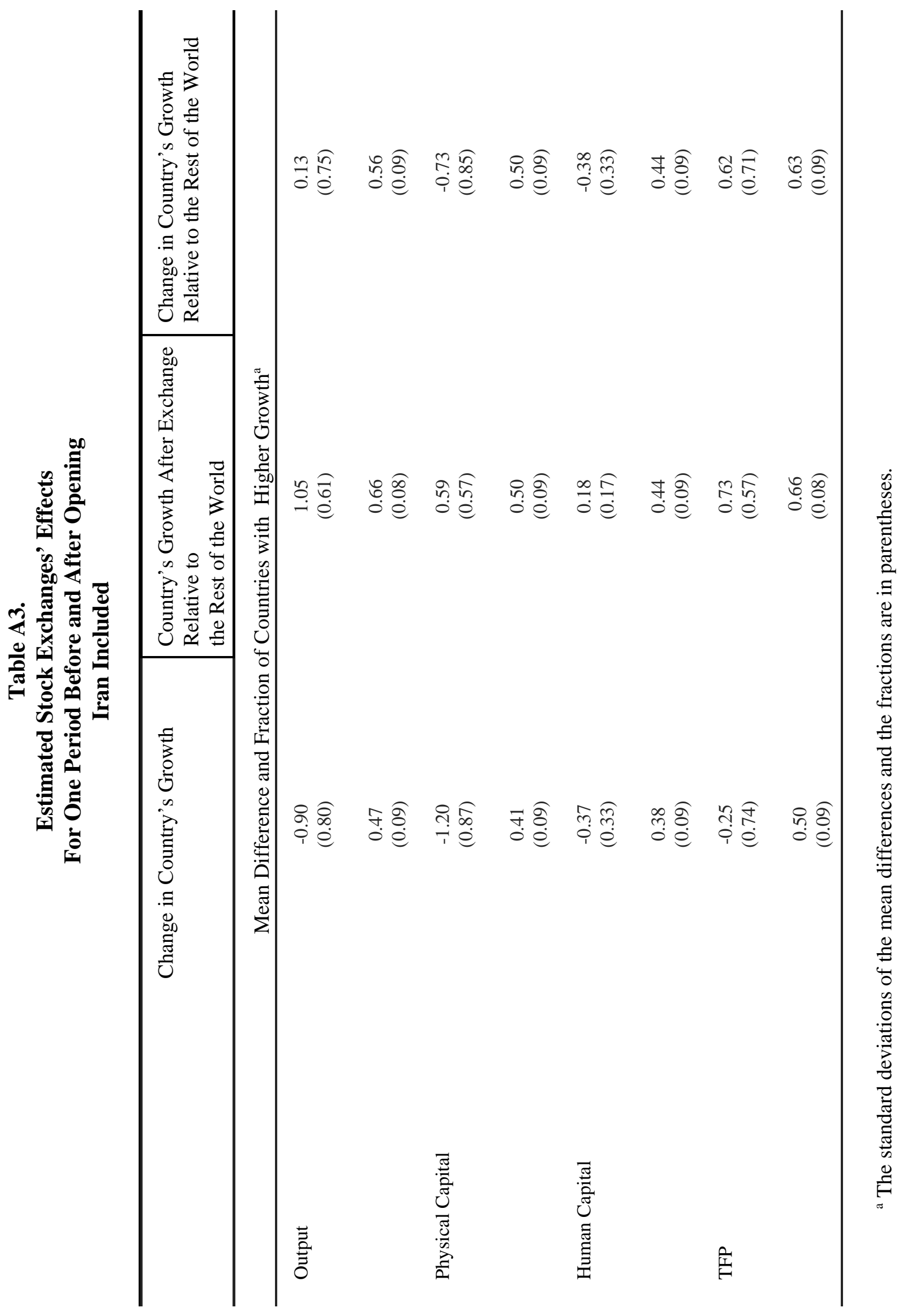




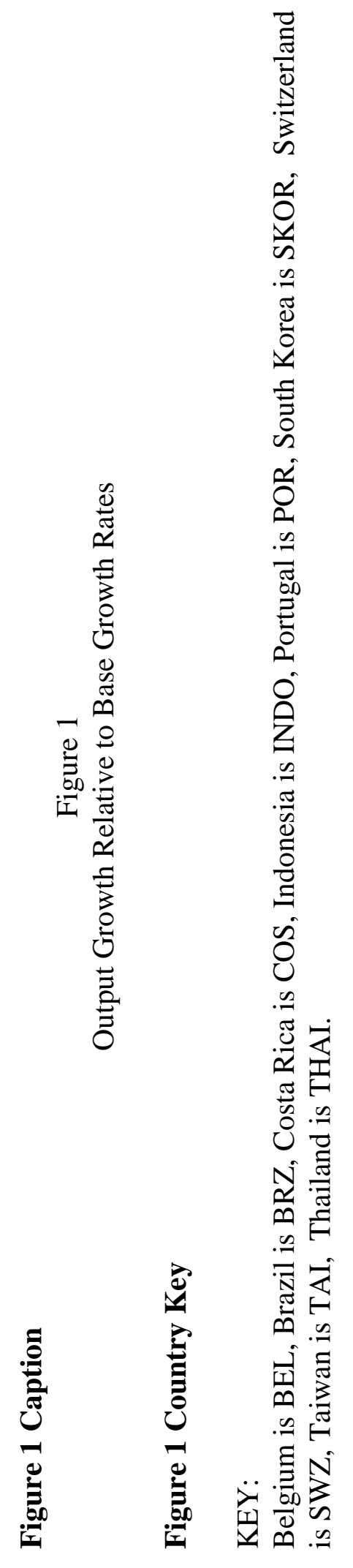



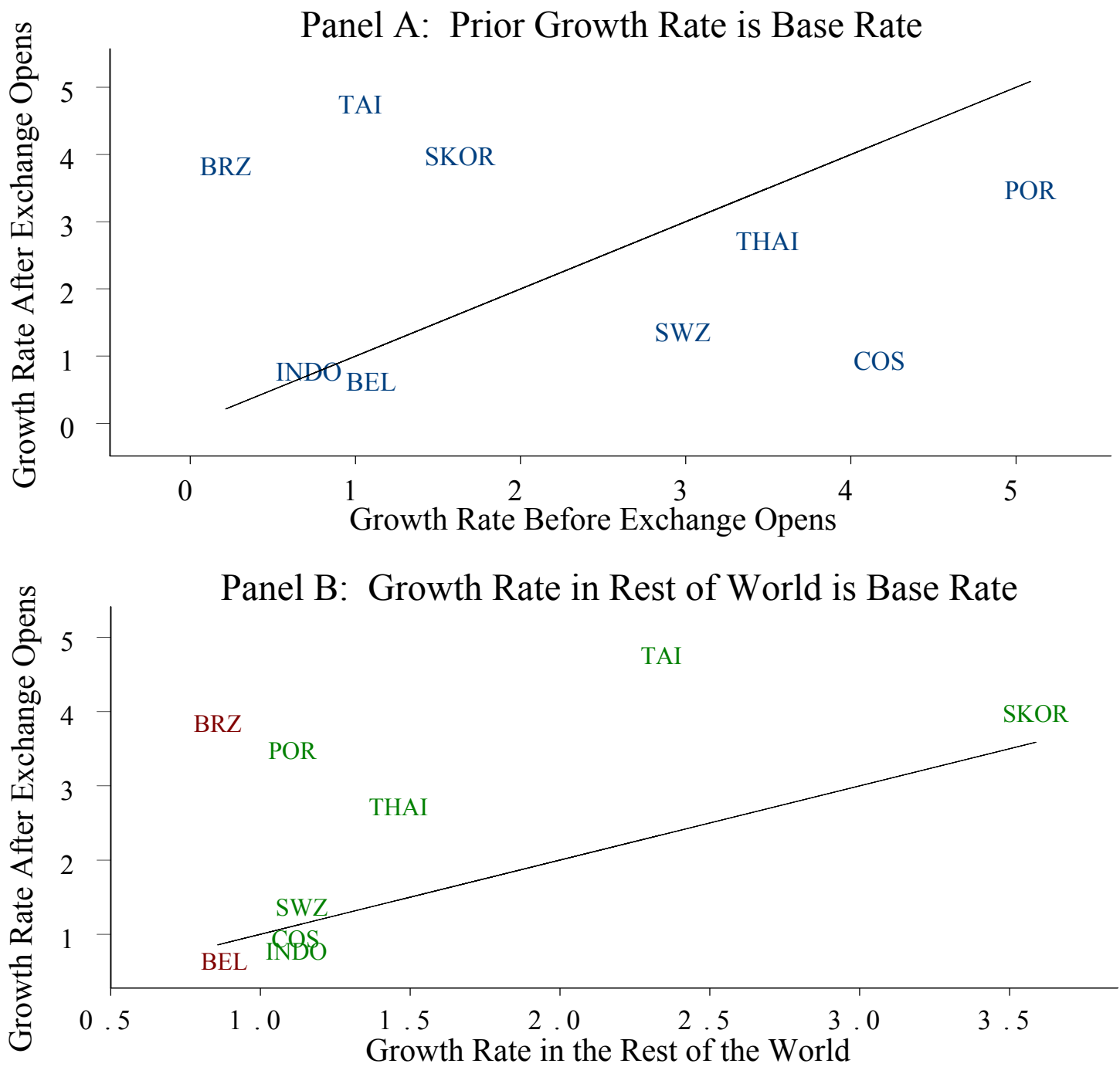

Panel C: Change in Growth Rate in the Rest of World is Base Rate BRZ TAI
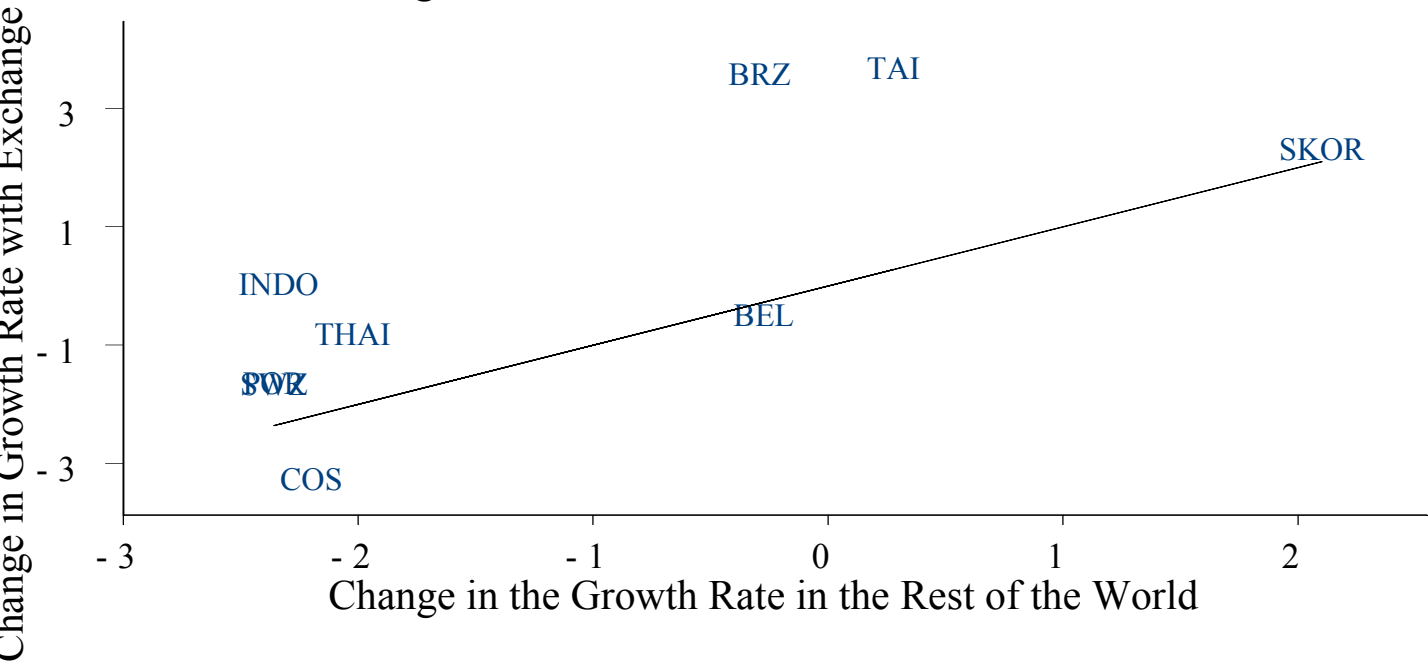

Change in the Growth Rate in the Rest of the World 